\title{
Relationship between well pattern density and variation function of stochastic modelling and database establishment
}

\author{
Jinkai Wang ${ }^{1,3},^{*}$, Kai Zhao ${ }^{2}$, Zhaoxun Yan ${ }^{4}$, Yuxiang $\mathrm{Fu}^{1}$, and Jun Xie ${ }^{1,3}$ \\ ${ }^{1}$ College of Earth Science and Engineering, Shandong University of Science and Technology, 266590 Qingdao, PR China \\ ${ }^{2}$ Research Institute of Petroleum Exploration and Development, 100083 Beijing, PR China \\ ${ }^{3}$ Laboratory for Marine Mineral Resources, Qingdao National Laboratory for Marine Science and Technology, \\ 266237 Qingdao, PR China \\ ${ }^{4}$ The Fourth Gas Production Plant, Changqing Oilfield Branch, PetroChina, 710021 Xi'an, PR China
}

Received: 28 May 2020 / Accepted: 15 September 2020

\begin{abstract}
For 3D geological modelling of oil and gas reservoirs, well pattern density is directly related to the number of samples involved in the calculation, which determines the variation function of stochastic modelling and has great impacts on the results of reservoir modelling. This paper focuses on the relationship between well pattern density and the variogram of stochastic modelling, selects the large Sulige gas field with many well pattern types as the research object, and establishes a variogram database of stochastic models for different well pattern densities. First, the well pattern in the study area is divided into three different types (well patterns A, B, and C) according to well and row space. Several different small blocks (model samples) are selected from each type of well pattern to establish the model, and their reasonable variogram values (major range, minor range and vertical range) are obtained. Then, the variogram values of all model samples with similar well pattern densities are analysed and counted, and the variogram database corresponding to each type of well pattern is established. Finally, the statistical results are applied to the modelling process of other blocks with similar well pattern density to test their accuracy. The results show that the reservoir model established by using the variation function provided in this paper agrees well with the actual geological conditions and that the random model has a high degree of convergence. This database has high adaptability, and the model established is reliable.
\end{abstract}

\section{Introduction}

Stochastic modelling is a commonly used geological modelling method. Its basic idea is to generate a series of optional and equal probability geological models based on the analysis of known points, which can be used to predict the attribute values of unknown areas between control points (known points) [1-3]. Stochastic modelling recognizes the uncertainty of the prediction results; that is, every new model is stochastic [4,5]. Therefore, a stochastic geological model should have many sister models (random realization) that exist at the same time. The random realizations of the same model generated under the same conditions may differ greatly from each other due to the variation function, and these differences merely reflect the geological uncertainty contained in the random model [6-8]. In addition, in terms of well pattern productivity prediction, uncertainty model analysis can help engineers choose better production strategies $[9,10]$. Figure 1 shows four different

\footnotetext{
* Corresponding author: wangjk@sdust.edu.cn
}

random implementations of the same model. It can be concluded from this figure that the differences among random models are relatively large due to the well point value and variation function, which shows that the reservoir prediction results have multiple solutions [11].

The theoretical basis of geological modelling is geostatistics, which includes three aspects: kriging algorithms, variograms and stochastic simulations [12, 13]. Geostatistics is based on the theory of regional variables and the variogram as the basic tool to study the distribution of sample points with random characteristics in spatial distribution [14]. Among them, the variogram is an important parameter that affects stochastic modelling. It is a statistical tool to quantitatively describe the spatial variability and is used to characterize the nature of how a variable changes with different spatial positions [15-17]. The variogram uses three main parameters, namely, range value, sill value and nugget value, to represent various spatial variation properties of regionalized variables [18-21]. In the process of modelling, the slope at the initial end of the variogram curve represents the stability of the variable; the larger the slope is, the more 


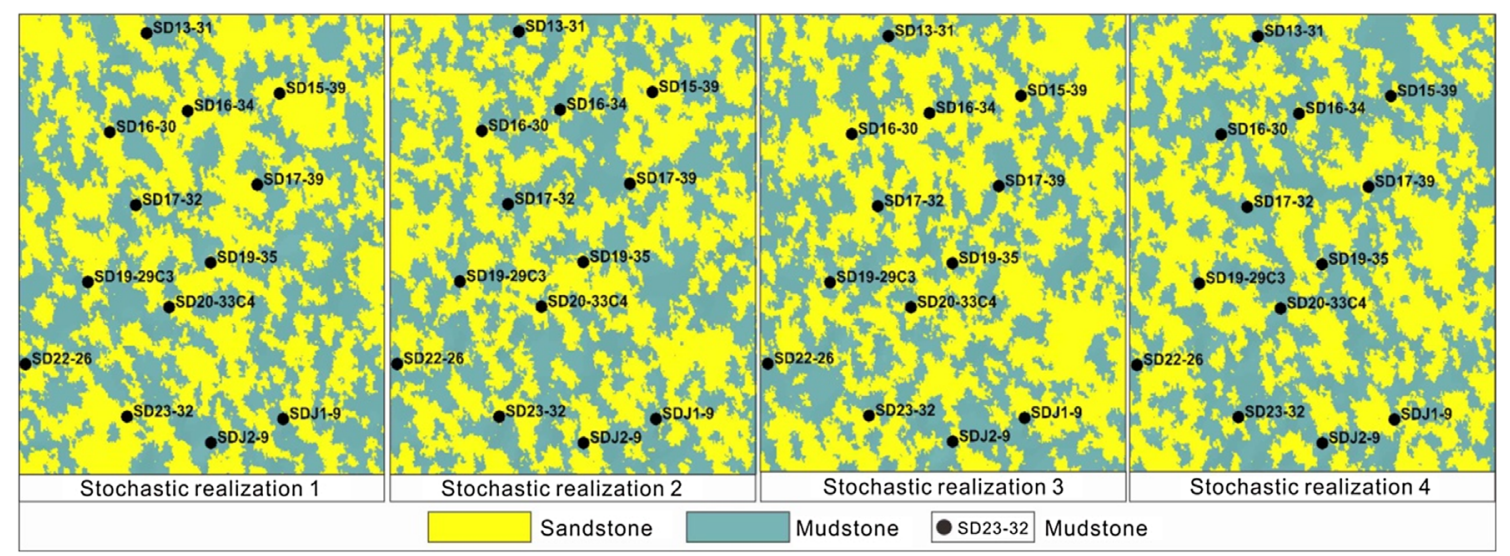

Fig. 1. Differences between the realizations of stochastic modelling.

unstable the variable, and the smaller the slope is, the smoother the variable [22]. In addition, some new techniques and methods have been developed gradually in the process of geological modelling, such as the magnetic random walk model, which can well predict the distribution of sand bodies and get accurate results, which is closer to the understanding of geological researchers [23].

Reservoir modelling is an application of geological modelling, which represents the distribution and change characteristics of reservoir structure and reservoir parameters in three-dimensional space, and the coupling relationship of all the model parameters [24]. The core problem of reservoir modelling is reservoir prediction between wells. Compared with other geological bodies, oil and gas reservoirs are controlled by a variety of parameters, such as complex rock structures, spatial configurations and spatial changes in reservoir parameters, which leads to multiple solutions of stochastic modelling [25-28]. The accuracy of reservoir stochastic modelling depends on the number of well points involved in interpolation. The more well points there are, the more representative the variogram function is, and the more the established model is in line with the actual geological situation. In contrast, the fewer well points there are, the weaker the adaptability of the variogram value obtained from data analysis, and the less representative the random model that can be established [29, 30].

For undeveloped oil and gas reservoirs, the well pattern density is small, the data points involved in interpolation calculation are few, and the prediction accuracy of the established model is low. It is necessary to use additional constraints to constrain the modelling process, such as interpretation of 3D seismic data, seismic inversion data volume and logging data, to improve the accuracy of the model [31-33]. Under the constraints of these additional conditions, the prediction accuracy of the attributes between the control points of the stochastic model can be greatly improved and closer to the actual geological situation $[34,35]$. However, for oil and gas reservoirs in a later stage of development, the well pattern density is generally large, and there are many data points involved in the modelling, which is conducive to obtaining a variation function with high reliability in the process of data statistics and to establishing a 3D geological model with high prediction accuracy [36]. In addition, reservoirs with large well pattern densities have always been highly researched, and various reservoir parameters, such as microfacies, lithofacies, and reservoir types, are well known, which can also be used to constrain the inter-well interpolation prediction in the modelling process. At present, the commonly used faciescontrolled modelling is a kind of random modelling method under the constraint of high-precision reservoir parameters. Its core is to use the plane distribution law and vertical evolution trend of sedimentary facies to constrain the modelling process, and it has become the leading technology and method of physical random modelling [37]. Some new methods, such as StoSAG algorithm, can adjust the optimization variables continuously to obtain the optimal variable value of the objective function and make the simulation results more accurate [38].

Comprehensive analysis shows that for sparse or dense well pattern reservoir modelling, obtaining a 3D geological model with high accuracy can be realized only by reasonable data analysis of well point values in the area and election of a suitable constraint condition. However, if a reservoir with a large area and an irregular well pattern (some areas have a large well pattern density, and other areas have a small well pattern density), it is difficult to establish a high-precision 3D geological model by using conventional methods because it is unrealistic to obtain a reasonable variation function suitable for all well patterns by data analysis. The Sulige gas field is such an area, which has a large area (more than $20000 \mathrm{~km}^{2}$ ), complex well pattern and great differences in well pattern density. For such a reservoir, is there an effective solution to build a high-precision prediction model? The answer, of course, is yes. In this paper, a special solution is designed to establish a high-precision 3D geological model of this kind of reservoir and to build a variogram database of reservoirs with different well patterns, which simplifies this type of reservoir modelling. 


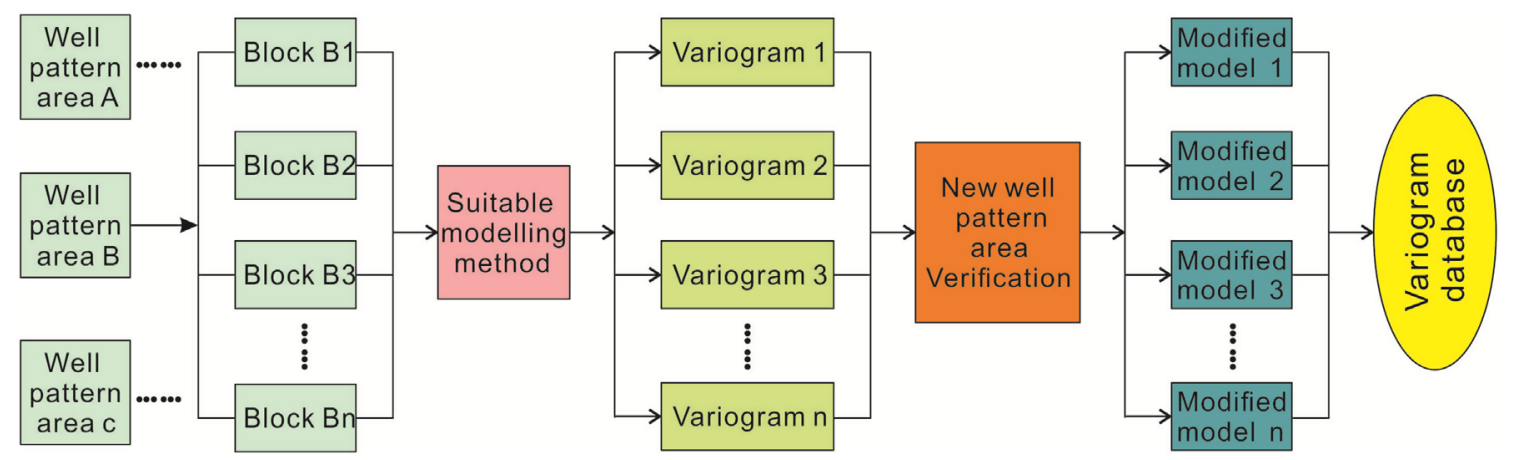

Fig. 2. Flow chart for the relationship between well pattern density and variogram.

\section{Material and methods}

The research area selected in this paper is the Sulige gas field. The data used in the research process are all real natural gas well data collected from Changqing Oilfield Company, including core data, rock analysis and testing data and logging data for these wells. These data provide the research basis for this paper and ensure the smooth development of various research tasks. After obtaining these data, we develop a unique research design to solve the problem of low accuracy of the gas reservoir model with a large range and great differences in well pattern density. The research idea is designed for the existing well pattern. First, cluster analysis is carried out according to the similarities in well pattern density, and the combinations of variogram parameters of sandstone and mudstone under different well pattern conditions are counted. Then, the combinations of well pattern density and variogram parameters are analysed by mathematical induction and other methods. Finally, the modelling variogram database of Sulige gas reservoir is obtained. The main technical ideas are as follows (Fig. 2):

1. The large study area is divided into three types according to well pattern density, and several different model samples are then established in each type to ensure that the well pattern density in each model sample is approximately the same.

2. Different modelling methods are used to build the geological model of each model sample. For example, the facies-controlled method is used in areas with high well pattern density, and the seismic and logging data volume constraint method is used in areas with low well pattern density.

3. The accuracy of each model is tested to ensure that the model established by the uniform well pattern is consistent with the actual geological situation.

4. The models of similar well pattern densities are classified as the same category, and the correlation of the variogram used in each model is statistically analysed. The regression formula is established, and the appropriate variogram range under the well pattern density is obtained.
5. The obtained variogram is applied to the new modelling area of similar well pattern density, and the prediction accuracy of these models is used to test the reliability of the database.

6. According to the verification results for a large number of test block models, the initial variogram database is adjusted, the relationship between well pattern density and variogram is optimized, and the accuracy of the database is improved.

\section{General situation of the study area}

The Ordos Basin is located in the central and western regions of China, with a nearly north-south trend. It can be divided into six first-order structural units: Yimeng uplift, Weibei uplift, Jinxi fold belt, Shanbei slope, Tianhuan depression and western margin thrust belt. The research area for this modelling is the Sulige gas field, which is located in the northern Ordos Basin. Its structural form is a west-dipping monocline, and the overall fluctuation of the strata is small. It is a super large gas field recently discovered in China. To establish the database of the relationship between the well pattern and the variogram, two representative well pattern areas, the XA block and GU block, are selected from the Sulige gas field. XU and GU are two blocks with similar development degree and almost equal total wells. These two blocks have well patterns in different development stages, which are very representative with well space ranging from $400 \mathrm{~m}$ to $1200 \mathrm{~m}$. These well patterns are in line with the requirements of this paper, and each type of well pattern can provide enough modelling samples. The initial variogram database is established by using the data from the GU area, then selecting different well pattern areas from the XA area for verification and adjustment, and finally establishing the appropriate high-precision variogram database of different well patterns (Fig. 3).

\section{Well pattern partition and sample modelling}

\subsection{Well pattern partition}

The Sulige gas field has the characteristics of a wide reservoir distribution, simple and gentle structure, and 


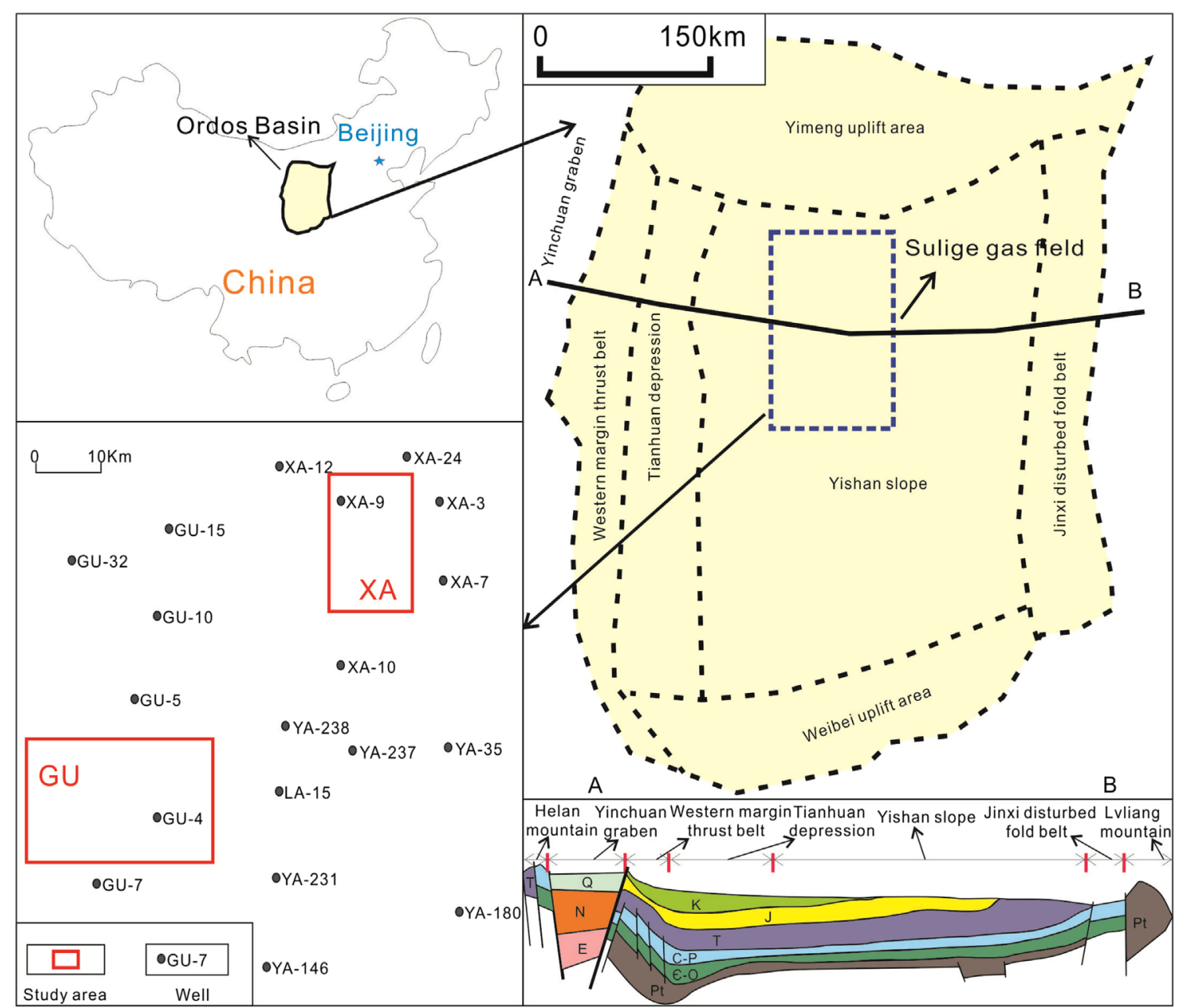

Fig. 3. Location map of the study area.

consistent sedimentary background. Within the framework of these favourable conditions, the sandstone drilling rate of gas wells is high. Therefore, it is feasible to quantitatively characterize the relationship between well pattern densities and variograms by geostatistics. The well pattern in the study area is irregular, and the well space is between $500 \mathrm{~m}$ and $1500 \mathrm{~m}$, so it seems that there is no condition for classification. However, from the perspective of the development stage of these wells, some regular phenomena will be found, because the density of well pattern is positively proportional to the development degree, that is, with the increase of development time, the density of well pattern is gradually increased. It can be concluded that there are three types of distances between these wells: $500 \mathrm{~m}$ (infill well pattern), $700 \mathrm{~m}$ (conventional well pattern) and $1000 \mathrm{~m}$ (initial well pattern). According to the distribution characteristics of the well pattern in the GU area, three types of well pattern density areas are identified, namely, well pattern area A, well pattern area B, and well pattern area C. Each type of well pattern area is divided into different numbers of model sample areas, including 6 in area A, 12 in area B and 15 in area C. See Table 1 for well space and row space data of well points in each model sample.
The subdivision into blocks reduces the uncertainty of the stochastic simulation caused by the difference in the well pattern distribution. The minimum well pattern density of the GU area is 0.8 well $/ \mathrm{km}^{2}$, and the maximum well pattern density is 3.5 well $/ \mathrm{km}^{2}$. Most of the model samples with large well pattern densities are located in the middle of the study area, and the peripheral well pattern density is relatively low. A total of 33 model samples are established, which are interspersed with each other and spread throughout the whole block (Fig. 4).

\subsection{Partition modelling (taking the sample model of area $A$ as an example)}

A model sample from area A is selected and named A1. First, the structural model of A1 is established, and then the random modelling of sandstone-mudstone is carried out to obtain the range value of the variation function and establish the database. The plane grid size of the A1 structural model is $20 \mathrm{~m} \times 20 \mathrm{~m}$, the longitudinal modelling thickness is $1 \mathrm{~m}$, the plane grid size is $350 \times 219$, the vertical direction has 108 layers, and the number of grids in the whole geological model is 8278200 . 
Table 1. Sample number and characteristics of three well pattern models.

\begin{tabular}{lccc}
\hline Unit name & Unit number & Well space $(\mathrm{m})$ & Row space $(\mathrm{m})$ \\
\hline Well pattern area A & 6 & $<600$ & $<700$ \\
Well pattern area B & 12 & $600-800$ & $700-900$ \\
Well pattern area C & 15 & $>800$ & $>900$ \\
\hline
\end{tabular}

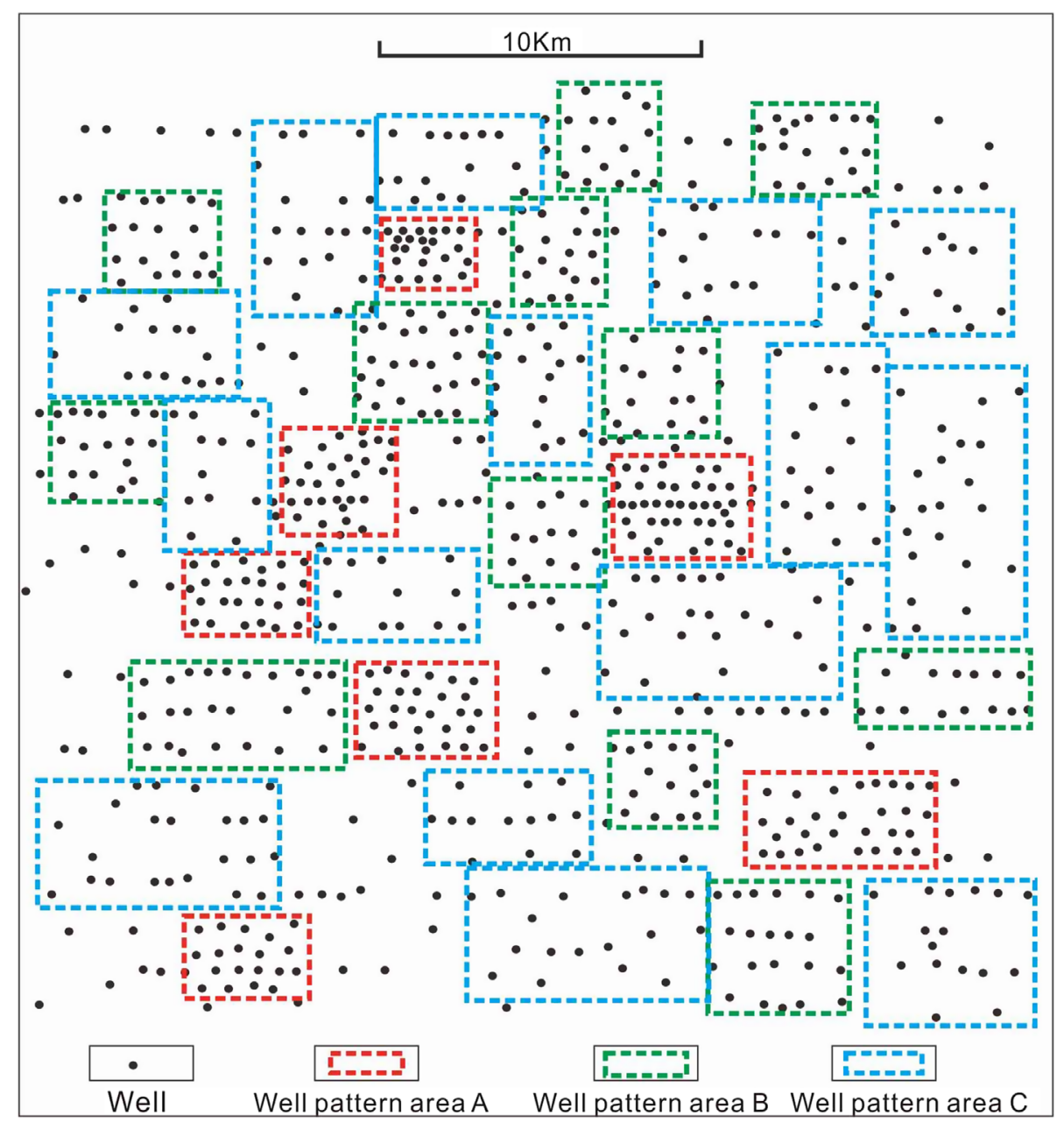

Fig. 4. Distribution of different types of model samples in the GU area.

\subsubsection{Data source}

In this paper, the lithofacies modelling data are the thicknesses of sandstone and mudstone at each well point in the area, which are represented by two numbers: 0 (sandstone) and 1 (mudstone). In this paper, the lithofacies modelling data are the thicknesses of sandstone and mudstone at each well point in the area, which are represented by two numbers: 0 (sandstone) and 1 (mudstone). These lithologic data are obtained by logging data interpretation. If multiple logging curves (such as gamma ray; acoustic; resistivity and so on) show the characteristics of sandstone, then its lithology code is defined as 0 , otherwise it is mudstone (code 1 ). In the vertical direction, these data are continuous and appear at intervals; in the plane, it is restricted by the well density. Lithology data is the basic data of lithofacies model. Figure 5 shows the lithofacies data obtained from two single wells.

There are 45 wells in block A1; that is, there are 45 data points in the plane that can be included in the numerical analysis in the modelling process. The thickness of the fine layer in the longitudinal direction is $1 \mathrm{~m}, 15-20$ layers make up a zone, and there are 7 zones in the model. The data points in these layers participate are used for the numerical analysis in the vertical direction (Fig. 6).

\subsubsection{Lithology distribution law}

The sandstone in the study area formed by fluvial sedimentation, with obvious positive rhythmic characteristics, and 


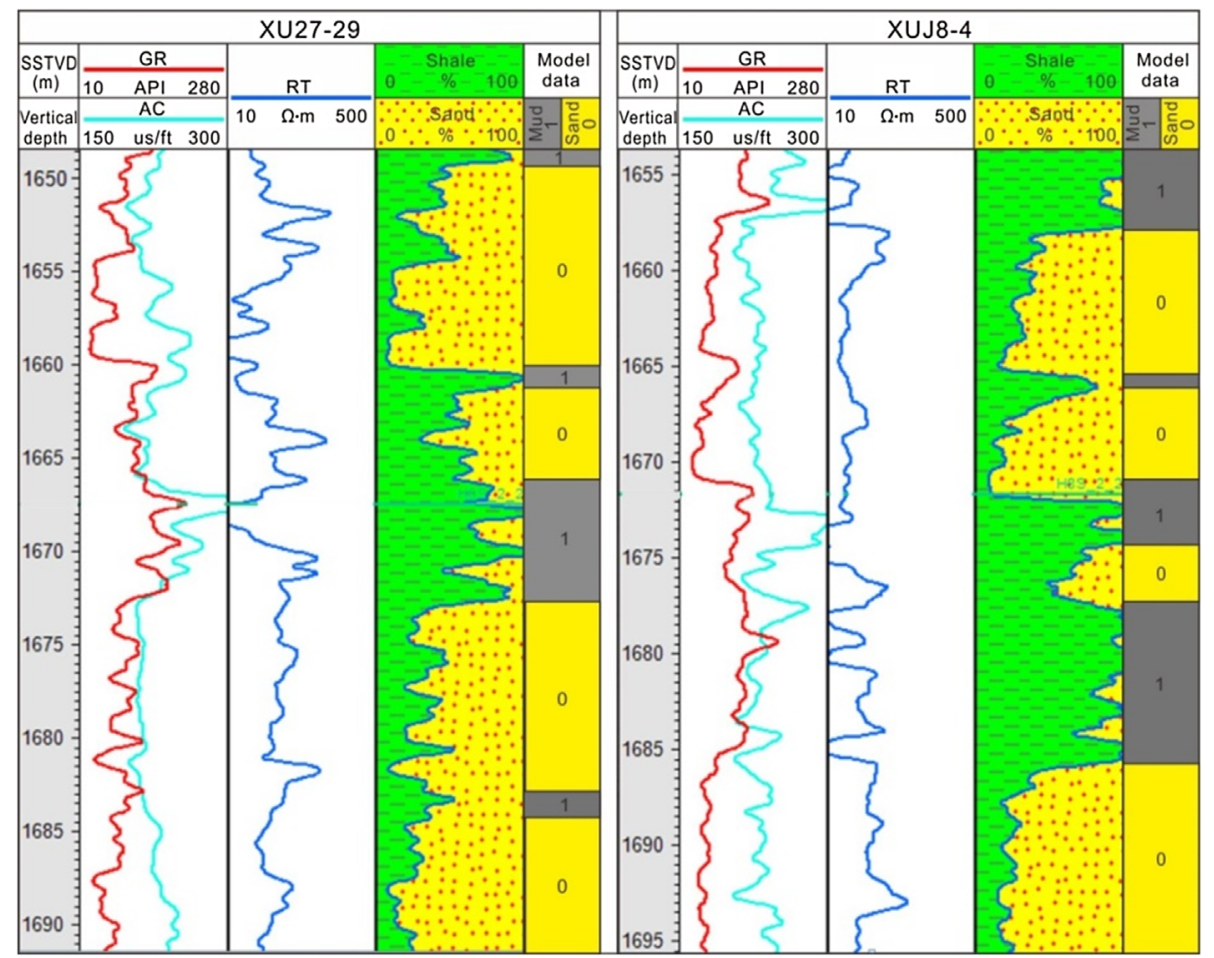

Fig. 5. Lithofacies data of single well.

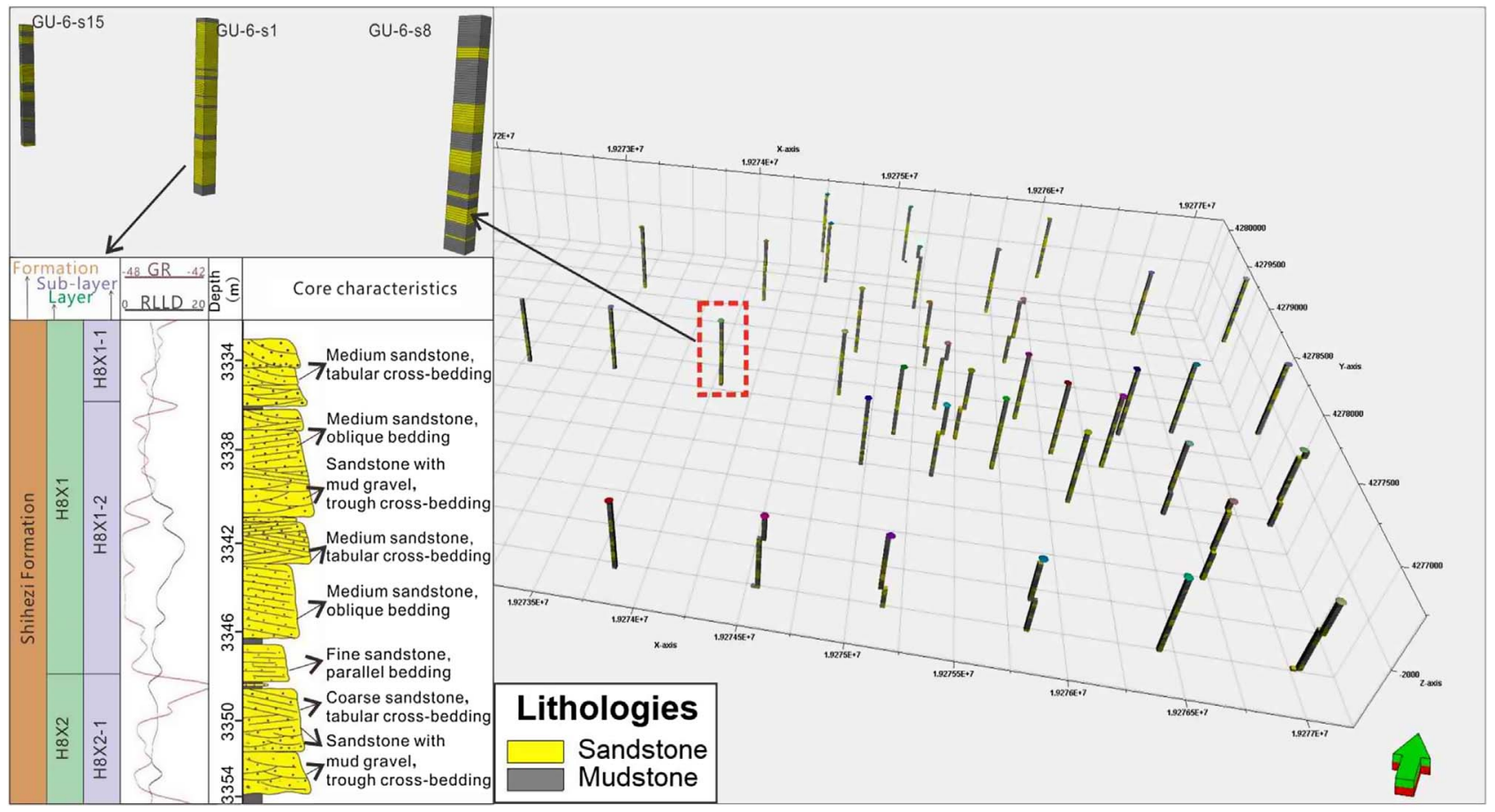

Fig. 6. Original data points of sandstone-mudstone lithofacies modelling.

thick sand bodies all formed by multi-stage superposed sedimentation (Fig. 7a). Before establishing the model, it is necessary to discretize the lithological (sandstone and mudstone) information from the well into the model and to establish the correlation between the well and the model. According to the distribution of the sand body after discretization, it has little difference from that of a single well and basically maintains the original state of the sand body 


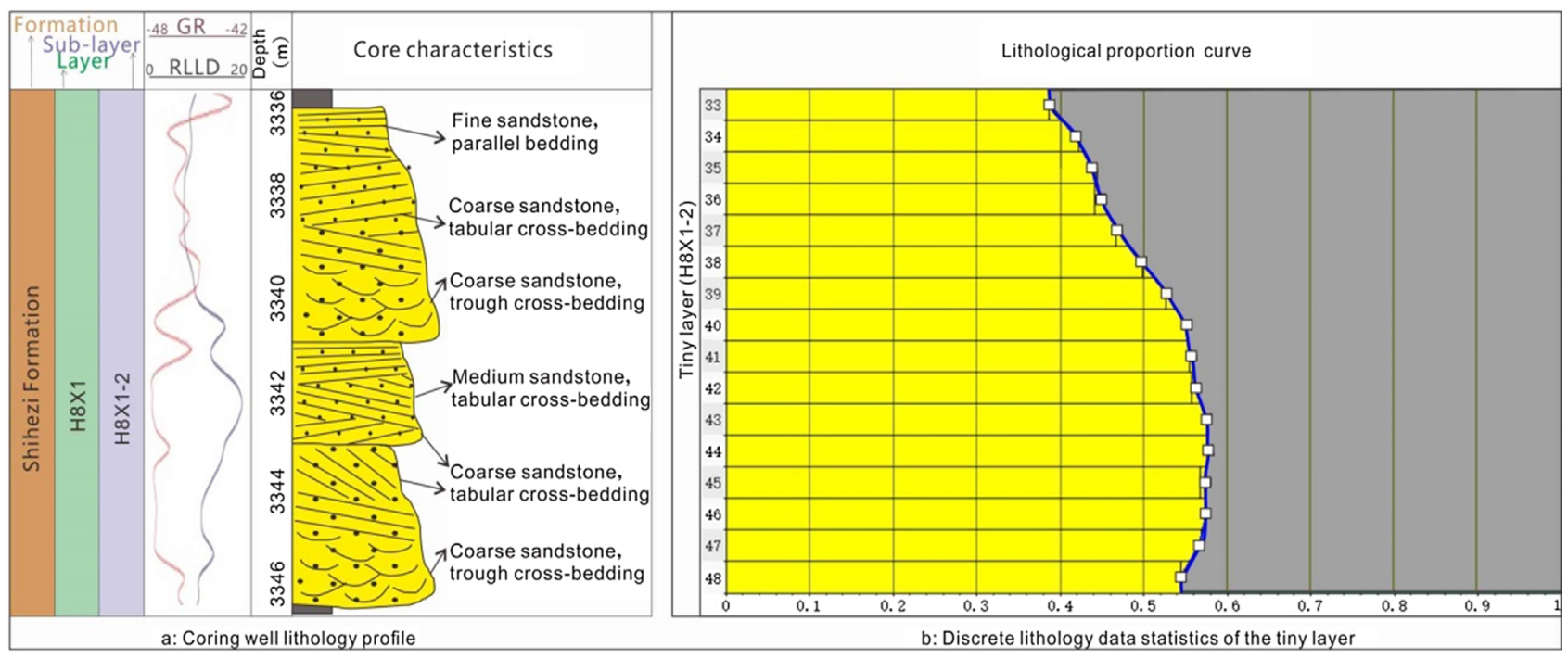

Fig. 7. Comparison of sandstone distributions between the vertical profile and the discrete model.

(Fig. 7b). This result shows that the actual data are entered into the model after various processing steps and do not change significantly until modelling, which is conducive to improving the accuracy of data analysis and the reliability of the model.

\subsubsection{Variation function setting}

The adjustment and setting of the variation function are done mainly to obtain the appropriate range value to represent the spatial correlations of regional variables. Beyond this range, the regionalized variables no longer have spatial correlation; that is, the observations beyond the range do not affect the estimation results for the estimated points. A relatively large range means that the observational data in this direction are correlated over a large range; otherwise, the correlation of variables along this direction is low (Fig. 8). The adjustment mainly follows the following principles:

1. For the adjustment of step size, the average well space, as well as its maximum and minimum values, should be considered.

2. The range of search steps should be limited within $60 \%$ of the block boundary and should be coordinated with the step size to ensure that there are enough data points in the search range.

3. The vertical search distance should be limited within the average thickness of a single sand body, and it is better to be equivalent to the thickness of the vertical subdivision layer set during modelling.

On the basis of the above principles, the variograms of sandstone and mudstone in each zone of the model are fitted, and reasonable variograms are obtained. For a thick continuous layer of sandstone, the data points are distributed evenly, the correlation is good, and the fitting effect of the variogram is good. However, for thin layers with small sandstone thickness and large mudstone thickness, the correlation of the control points is poor, and the fitting degree of the variogram is slightly poor. On the basis of variogram fitting, a high-precision $3 \mathrm{D}$ geological model is established.

\section{Study of the variation function relationship of different well patterns}

\subsection{Well pattern area $A(600 \times 700 \mathrm{~m})$}

After the adjustment principle of the variogram is set, the same operation process is carried out. The variogram is adjusted according to the well pattern characteristics of different blocks, and the lithofacies models of the remaining five samples are established. The distributions of sandstone and mudstone in the models are similar to the actual geological situation, which shows that the obtained variogram value has high adaptability. Table 2 shows the variogram values used in the different models.

The data in Table 2 are analysed using statistical methods and their distribution frequency chart, and the relationship between the major and minor range are established (Fig. 9). It can be seen from the figure that the main frequency of the distribution of the primary variable is approximately 750 , the main frequency of the secondary variable is approximately 620 , and there is a good linear relationship between them. These results show that the sand bodies formed by fluvial facies deposition correspond well (with a certain proportion) in the flow direction and the vertical flow direction, and the length/width ratio of the inner bank and the side bank of the river channel has a compound normal distribution. In addition, the dominant frequency of vertical variation is approximately 5.0, which is basically equivalent to the thickness of a single sand body 

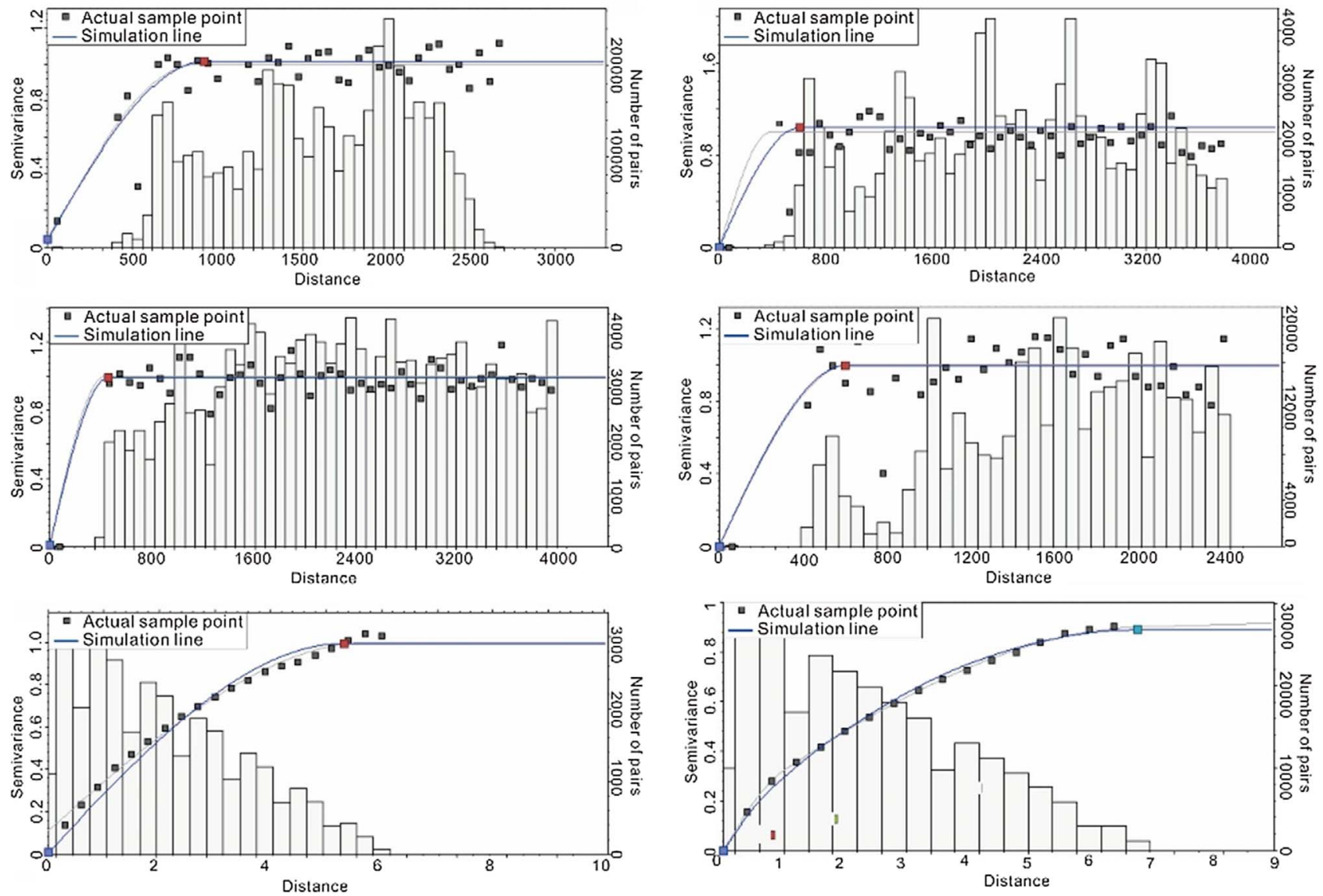

Fig. 8. Fitting curves for the variograms of sandstone in one zone.

Table 2. Range of values for model samples in area A.

\begin{tabular}{|c|c|c|c|c|c|c|c|c|c|}
\hline \multirow{2}{*}{$\begin{array}{l}\text { Variogram } \\
\text { range }\end{array}$} & \multirow{2}{*}{$\begin{array}{l}\text { Well pattern } \\
\text { area A }\end{array}$} & \multicolumn{8}{|c|}{ Layers } \\
\hline & & H8S1-1 & H8S1-2 & H8S2-1 & H8S2-2 & H8X1-1 & H8X1-2 & H8X1-3 & H8X2-1 \\
\hline \multirow{6}{*}{ Major range } & A1 & 734.1 & 932.1 & 600.1 & 781.5 & 767.1 & 810.1 & 940.2 & 837.3 \\
\hline & $\mathrm{A} 2$ & 794.2 & 841 & 786 & 833.7 & 846.1 & 771.3 & 865.2 & 940 \\
\hline & A3 & 524.1 & 614.3 & 535.4 & 620.3 & 551.7 & 566 & 506.5 & 574.2 \\
\hline & $\mathrm{A} 4$ & 756.8 & 803.4 & 1010 & 861 & 731.4 & 686 & 887.6 & 713 \\
\hline & A5 & 680 & 706 & 697 & 733.6 & 801.7 & 780 & 955 & 993 \\
\hline & $\mathrm{A} 6$ & 1032 & 1176 & 1086 & 1052 & 917 & 1014.3 & 1164.3 & 1085.4 \\
\hline \multirow[t]{6}{*}{ Minor range } & $\mathrm{A} 1$ & 580.4 & 733.5 & 542.3 & 491.2 & 716.1 & 631.7 & 603.3 & 675 \\
\hline & $\mathrm{A} 2$ & 551.7 & 547.6 & 506.2 & 624.9 & 666.4 & 664.7 & 696.4 & 811.3 \\
\hline & A3 & 516.8 & 587.2 & 490.5 & 500 & 500 & 536.8 & 501.2 & 482.1 \\
\hline & A4 & 746.9 & 690 & 736 & 582 & 657 & 511 & 621 & 577 \\
\hline & A5 & 544 & 626 & 527 & 557 & 743.5 & 623 & 717 & 706 \\
\hline & $\mathrm{A} 6$ & 691 & 871 & 973 & 627 & 857 & 801.4 & 633 & 850.7 \\
\hline \multirow[t]{6}{*}{ Vertical range } & A1 & 4.66 & 5.91 & 4.06 & 4.50 & 5.28 & 5.11 & 5.45 & 5.37 \\
\hline & $\mathrm{A} 2$ & 4.76 & 4.91 & 4.57 & 5.17 & 5.37 & 5.10 & 5.54 & 6.22 \\
\hline & A3 & 3.71 & 4.28 & 3.65 & 3.98 & 3.74 & 3.93 & 3.59 & 3.75 \\
\hline & $\mathrm{A} 4$ & 5.36 & 5.31 & 6.18 & 5.10 & 4.94 & 4.24 & 5.34 & 4.58 \\
\hline & A5 & 4.34 & 4.74 & 4.34 & 4.58 & 5.50 & 4.98 & 5.93 & 6.02 \\
\hline & A6 & 6.09 & 7.25 & 7.32 & 5.92 & 6.31 & 6.44 & 6.33 & 6.87 \\
\hline
\end{tabular}




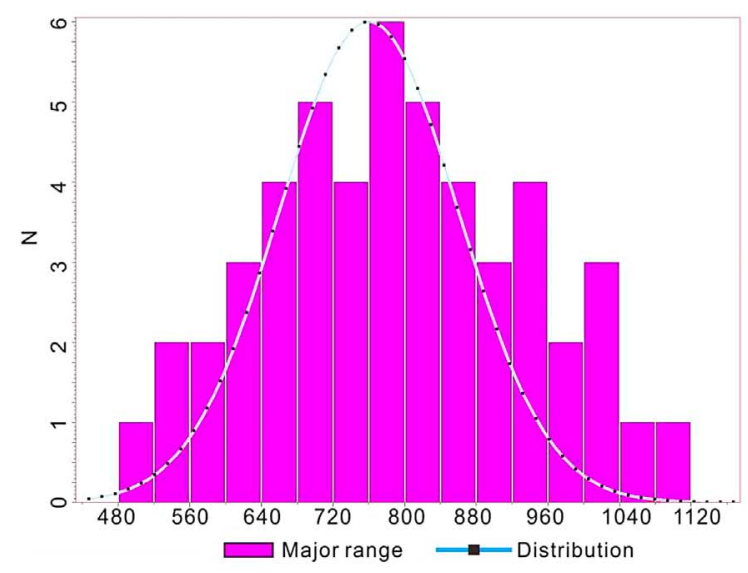

a: Distribution law of major range value

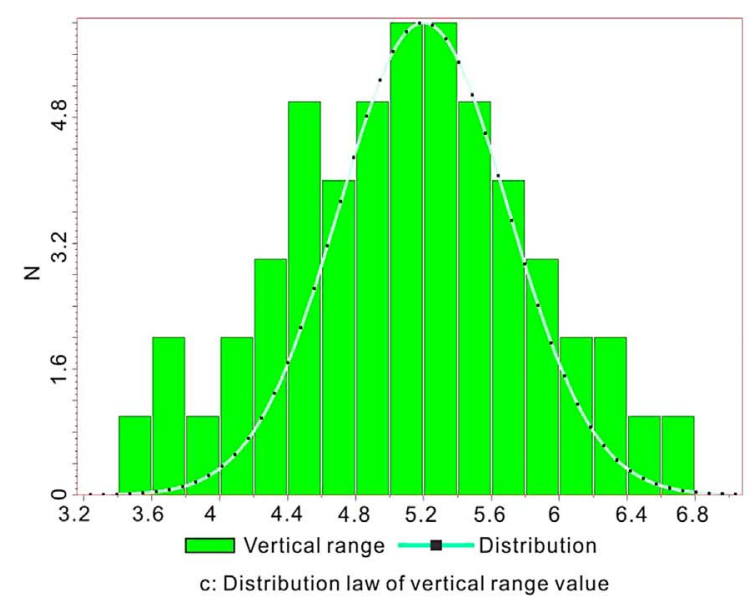

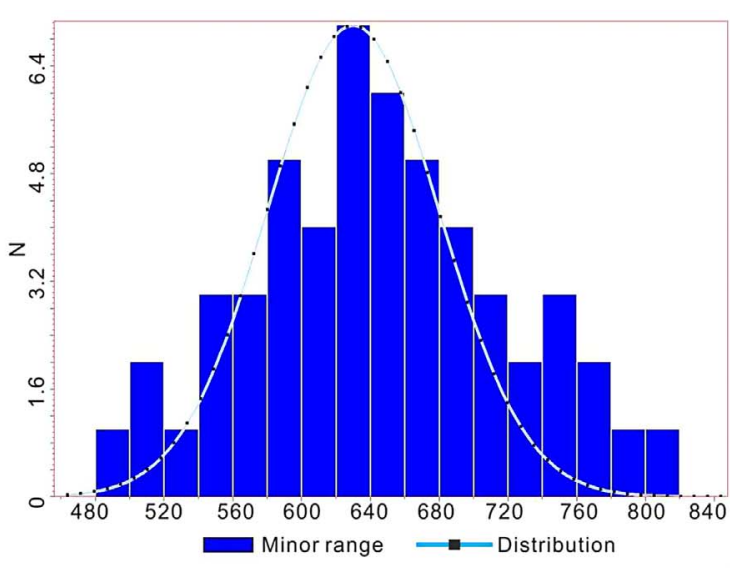

b: Distribution law of minor range value

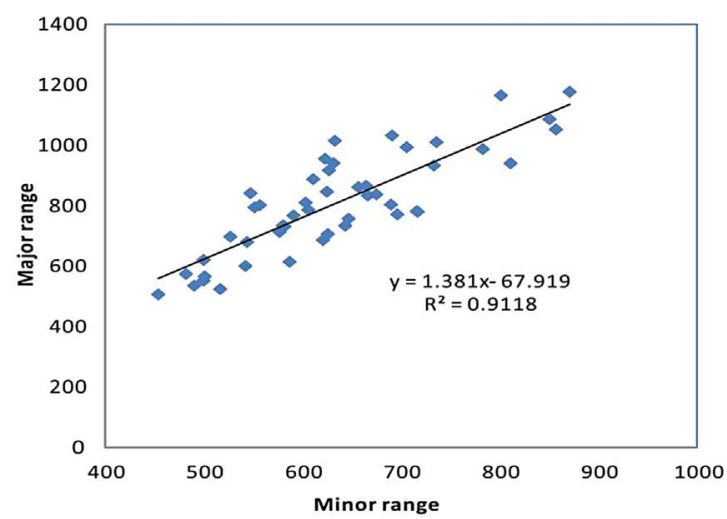

d: Correlation between major and minor range value

Fig. 9. Statistical analysis and correlation of range values in zone A.

in most wells; this result shows that the vertical correlation of sample points is not related to the well pattern but is only controlled by the thickness of a single sand body and the composite normal distribution law.

\subsection{Well pattern areas B and C $(600 \times 700 \mathrm{~m})$}

By using the same modelling method, the variogram values of each model sample in areas B and $\mathrm{C}$ are calculated, and they are statistically analysed. It can be concluded that the major and minor range values of the model samples in these two well pattern areas have composite normal distribution characteristics, and both increase gradually with the decrease in well pattern density, with an increase of $20-30 \%$ each time. The main transformer in area B is 961, and the secondary transformer is 749 (Fig. 10a); the main transformer in area $\mathrm{C}$ is 1180 , and the secondary transformer is 968 (Fig. 10b).

It can also be concluded from the correlation of the major and minor ranges of areas $\mathrm{B}$ and $\mathrm{C}$ that the correlation between them is relatively good and shows an obvious linear relationship. This result also indicates that the scale of the river channel is relatively large, and even the well pattern with the largest well space doesn't exceed the river channel boundary (Fig. 11).

\subsection{Relationship between variograms and well patterns}

By comparing the variogram values of all model samples in areas $\mathrm{A}, \mathrm{B}$ and $\mathrm{C}$, it can be found that with increasing well space, the reasonable variogram range value also increases (both the major and minor ranges); when the well space increases from $600 \mathrm{~m}$ to $1100 \mathrm{~m}$, the major range increases by $55 \%$, and the minor range increases by nearly $50 \%$. These results show that as the distance between two adjacent wells increases, the sand body size calculated by the model also increases, but it still does not exceed the actual sand body boundary (Fig. 12).

The vertical range value which is mainly affected by the content of sand and mudstone in the formation controls the vertical correlation and interpolation result of variables. If the proportion of sandstone is high, the thickness of sand body in the vertical direction of the new generation model will be large with good continuity. However, the vertical range value seems to have a poor correlation with the well pattern density on the plane. With the change in well space, the vertical variation does not change much. Its main frequency value is maintained between 4.5 and 5.6, and the variation amplitude is small, which indicates that the thickness of the sand body in the vertical direction is 


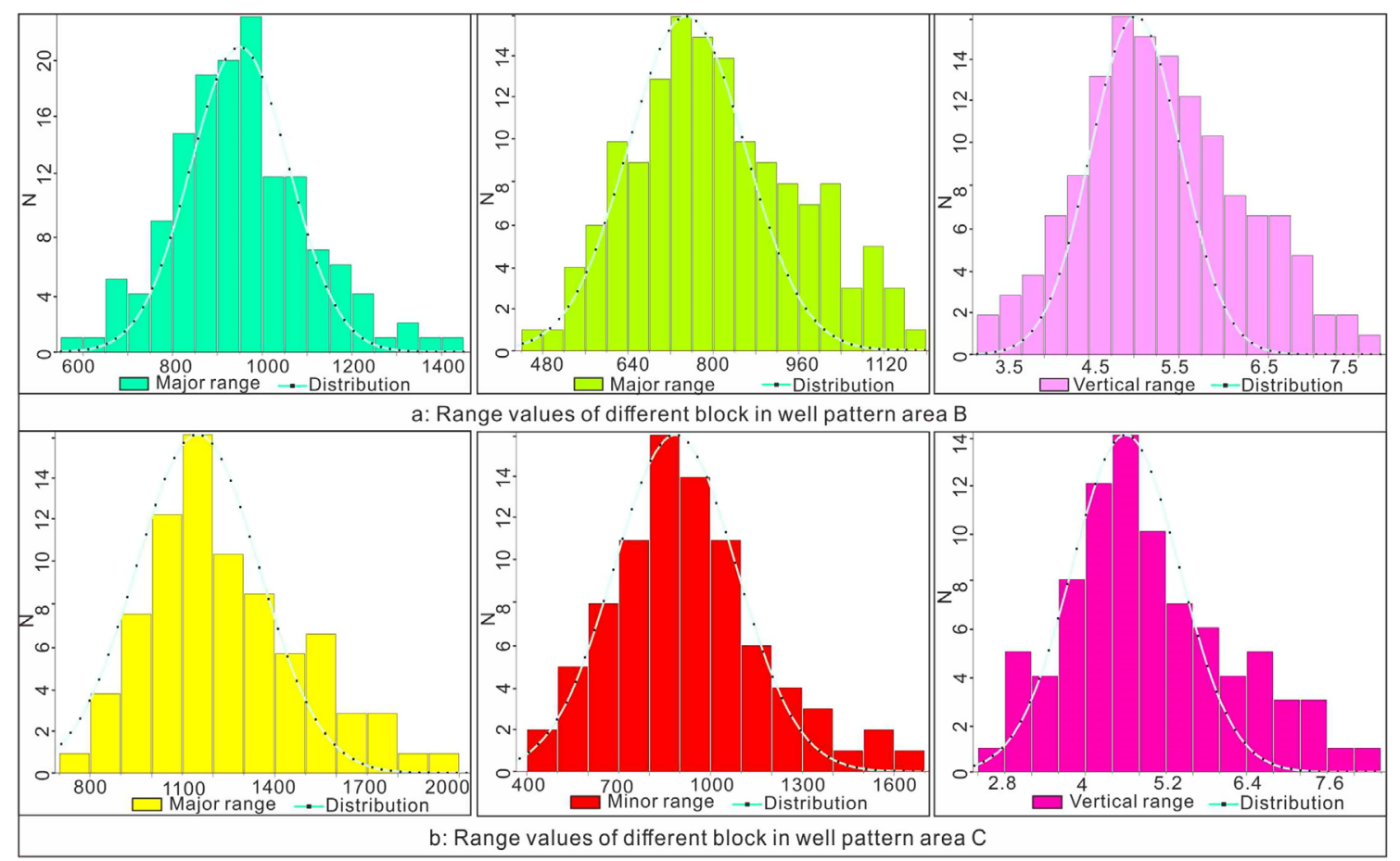

Fig. 10. Statistical analysis chart of variable range values of areas B and C.

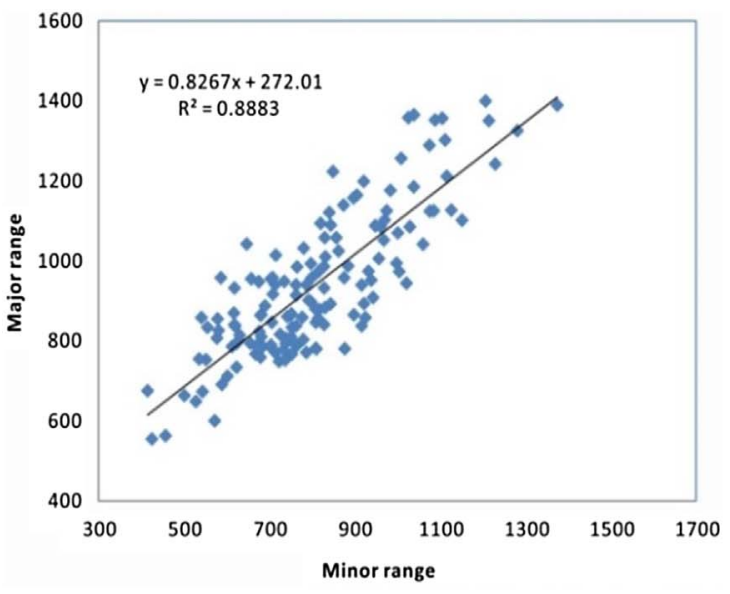

a: Correlation between major and minor range value of well pattern area $B$

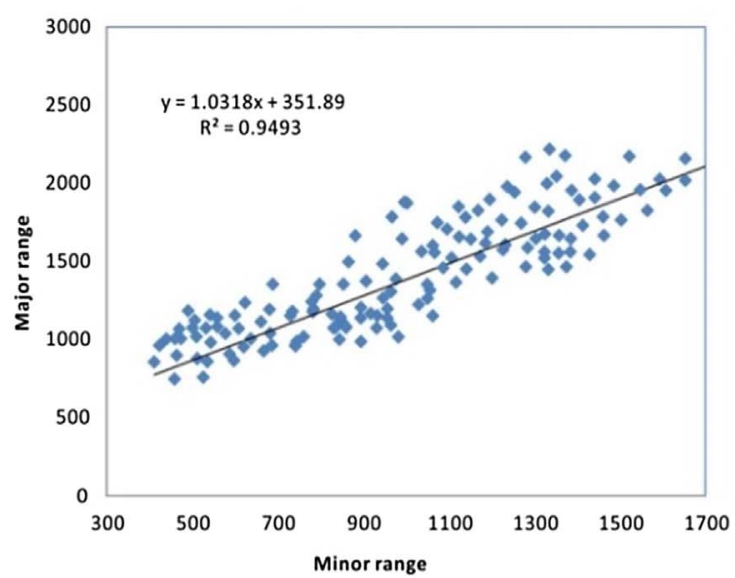

b: Correlation between major and minor range value of well pattern area $\mathrm{C}$

Fig. 11. Correlation between the primary and secondary ranges of areas B and C.

relatively stable and has little correlation with the well space (Fig. 13).

\section{Establishment and test of variogram database of different well patterns}

\subsection{Reasonable variation function values of different well patterns}

Through the statistical analysis of the variogram range values of all model samples, the reasonable variogram range values of each well pattern density area are determined. There is a positive correlation between the major and minor range values and the well pattern density (the variation range is approximately $20-30 \%$ ), while the vertical variogram value has little relationship with the well pattern density (Tab. 3).

\subsection{Variogram database test (taking area A as an example)}

The Sulige gas field covers a large area, and the GU block is used to build the variogram database. To test the reliability 

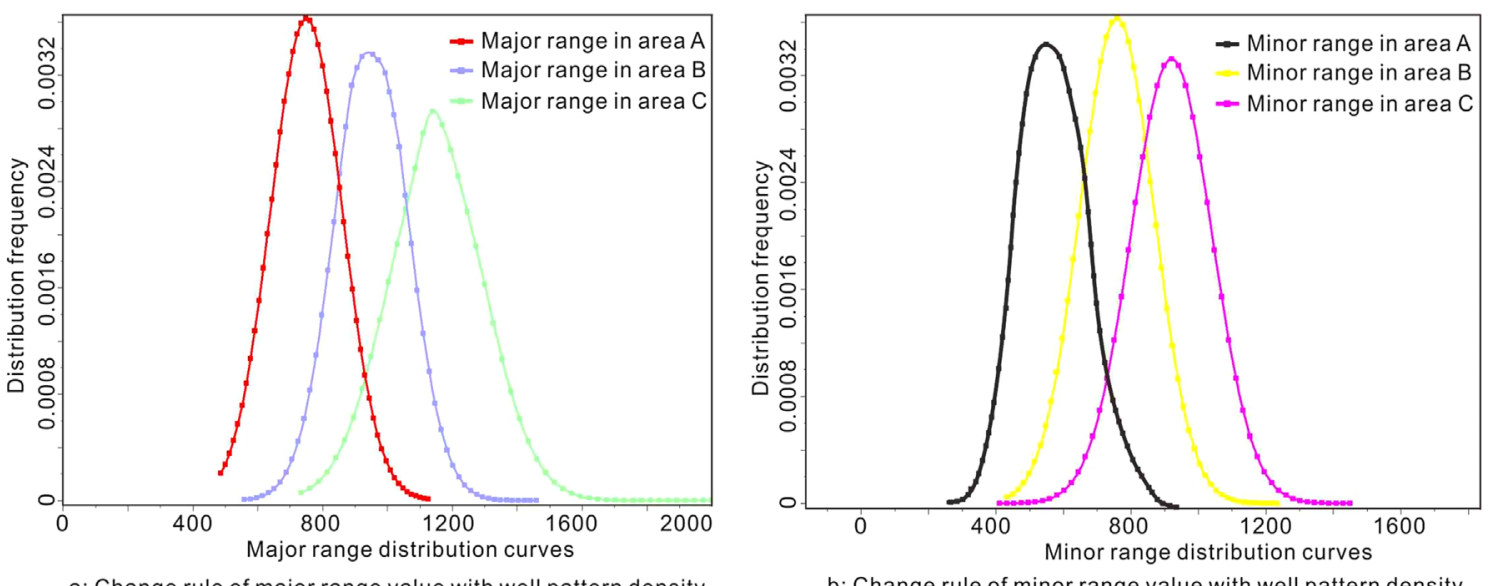

Fig. 12. Variation law of the major and minor ranges with the well pattern density.

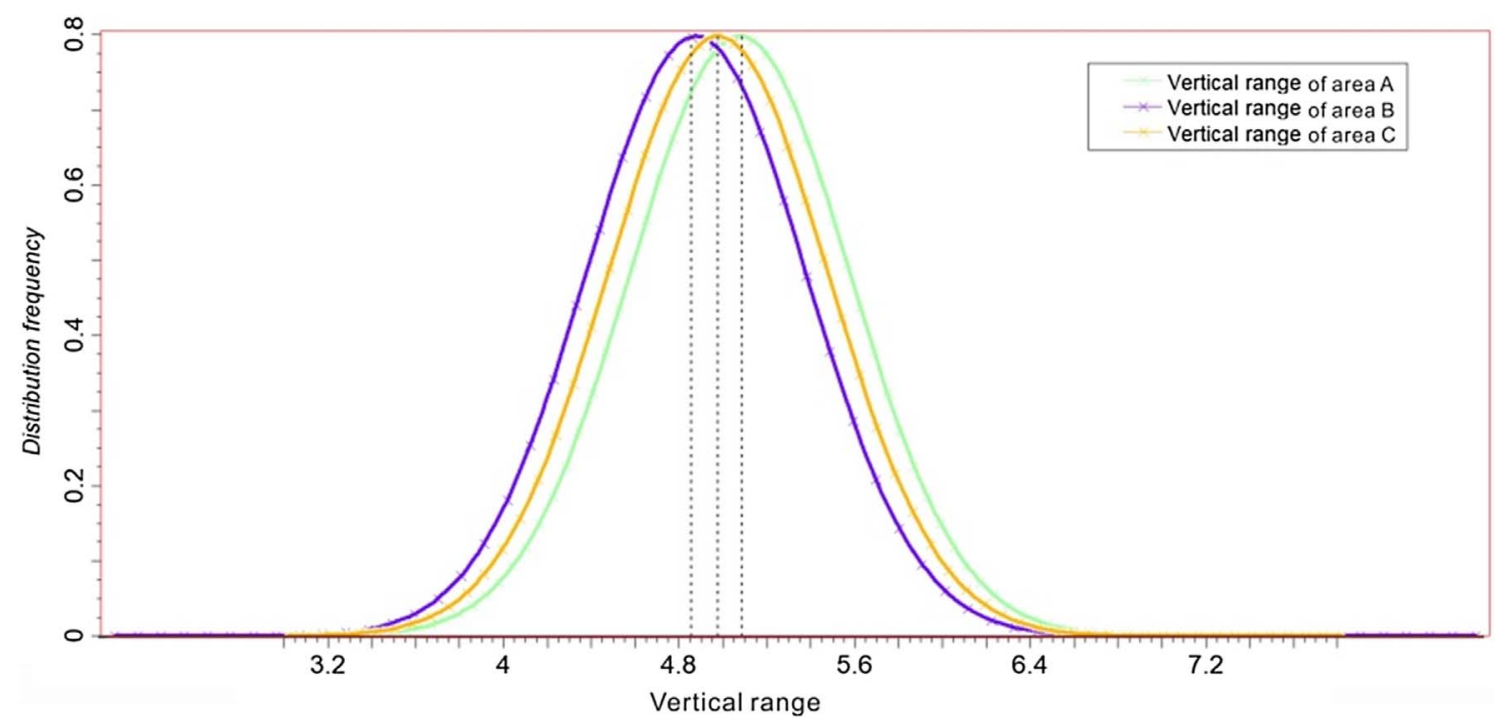

Fig. 13. Variation law of vertical range value with well pattern density.

Table 3. Reasonable range value of the variogram under different well pattern densities in the Sulige gas field.

\begin{tabular}{lccc}
\hline Unit name & $\begin{array}{c}\text { Major } \\
\text { range }\end{array}$ & $\begin{array}{c}\text { Minor } \\
\text { range }\end{array}$ & $\begin{array}{c}\text { Vertical } \\
\text { range }\end{array}$ \\
\hline Well pattern area A & 756 & 639 & 5.2 \\
Well pattern area B & 961 & 749 & 4.9 \\
Well pattern area C & 1180 & 968 & 5.1 \\
\hline
\end{tabular}

of the established database, the XA block northeast of the GU block is selected for verification (Fig. 14). The well pattern similarity of these two blocks is very high. There are dense well patterns with small well space and sparse well patterns with large well space. Thus, the XA block is suitable for the adaptability verification of the variation function of different well patterns.

\subsubsection{Establishment of lithofacies model}

The reasonable variation function values in Table 3 are directly applied to the lithofacies model establishment process using test samples with corresponding well patterns, and the random modelling method is used for interpolation calculation. Finally, lithofacies models of all test areas are established. Figure 15 is a representative block lithofacies model of area A.

\subsubsection{Model test}

To ensure the reliability of the established variogram database, it is necessary to perform a lithofacies model precision validation of each test sample. The test methods used are the well thinning method and the random model convergence method [39]. There are two kinds of well thinning methods: one is single well thinning, and the other is multiwell thinning. Figure 15 shows the test results for single-well thinning. In the modelling process, well XA30-M20 is 


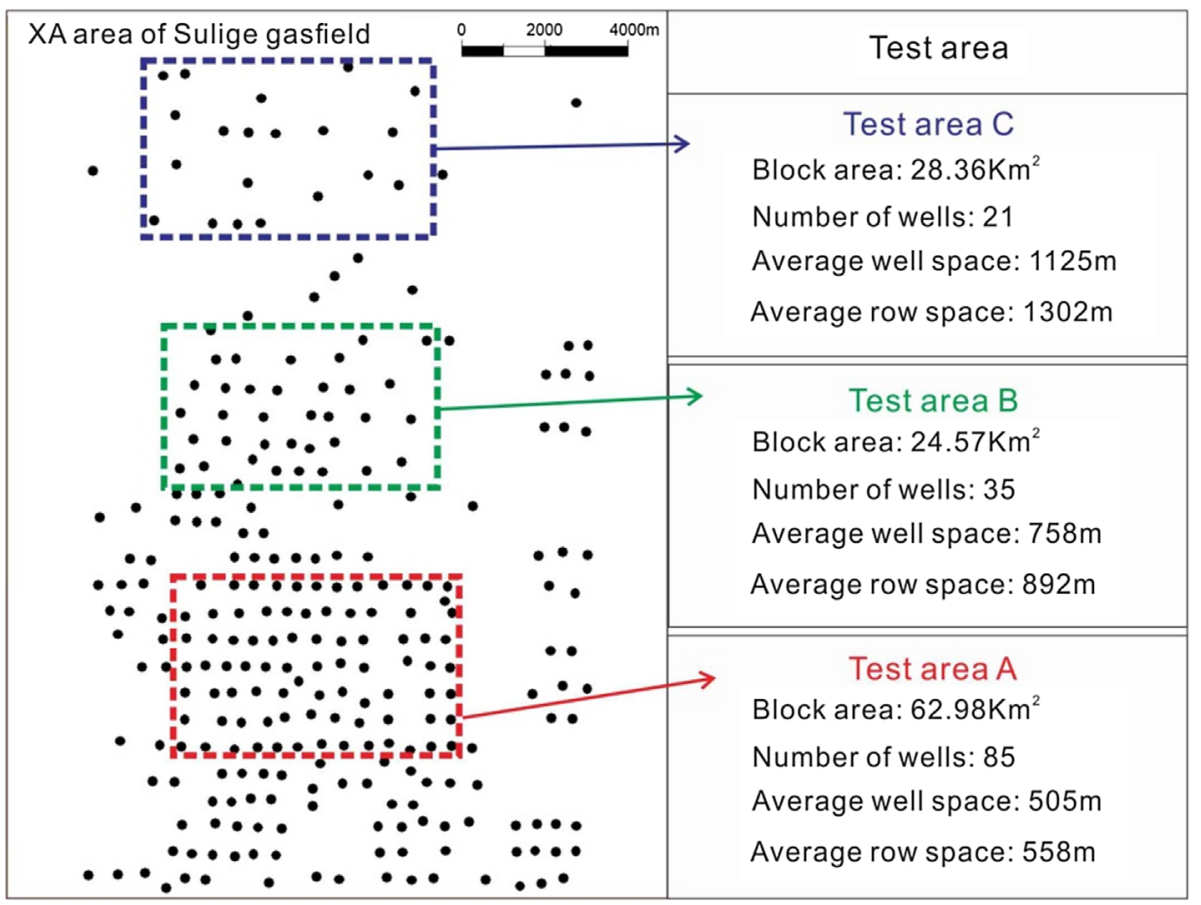

Fig. 14. Different validation model samples of the XA block.

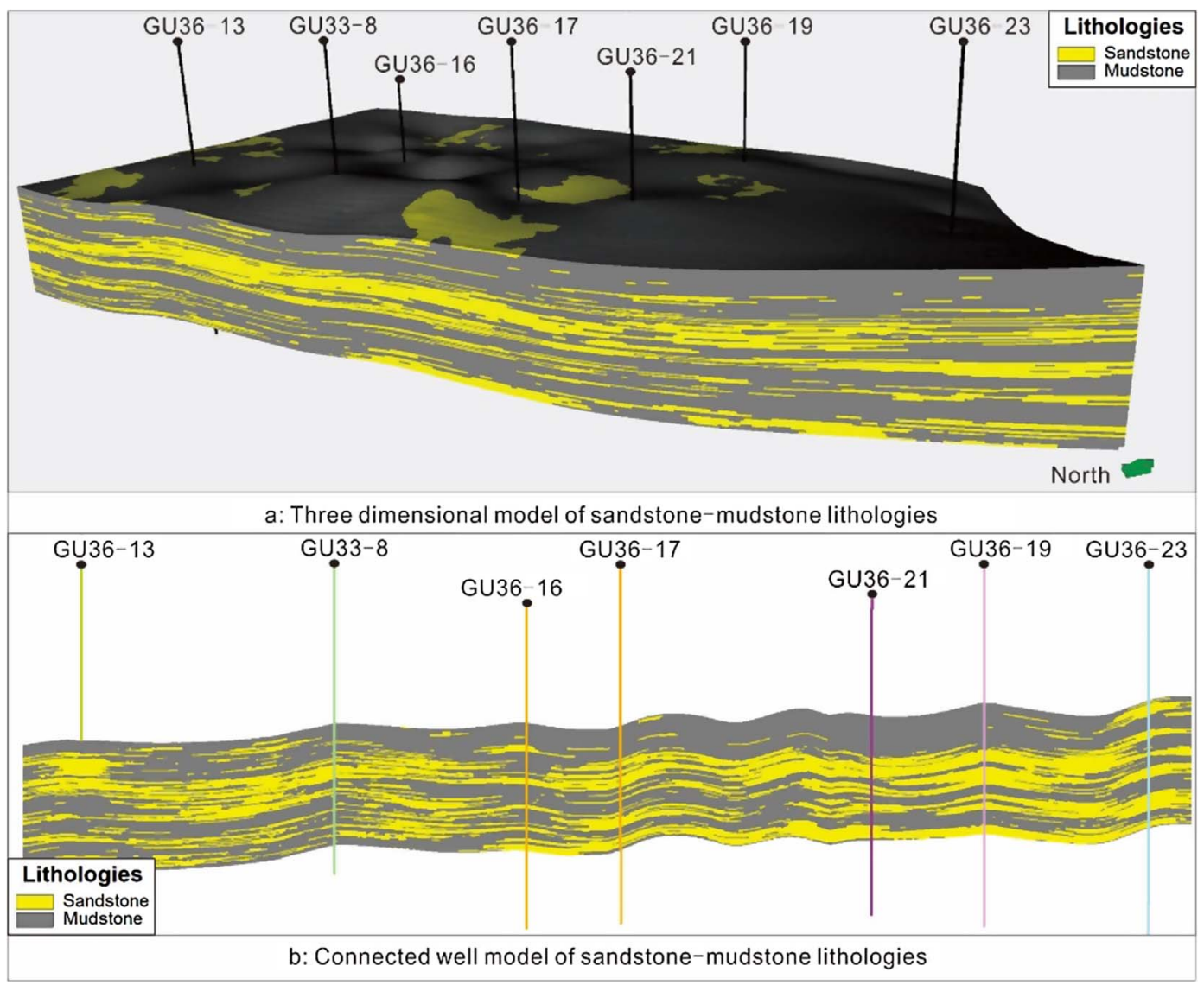

Fig. 15. Lithofacies model of validation area A. 


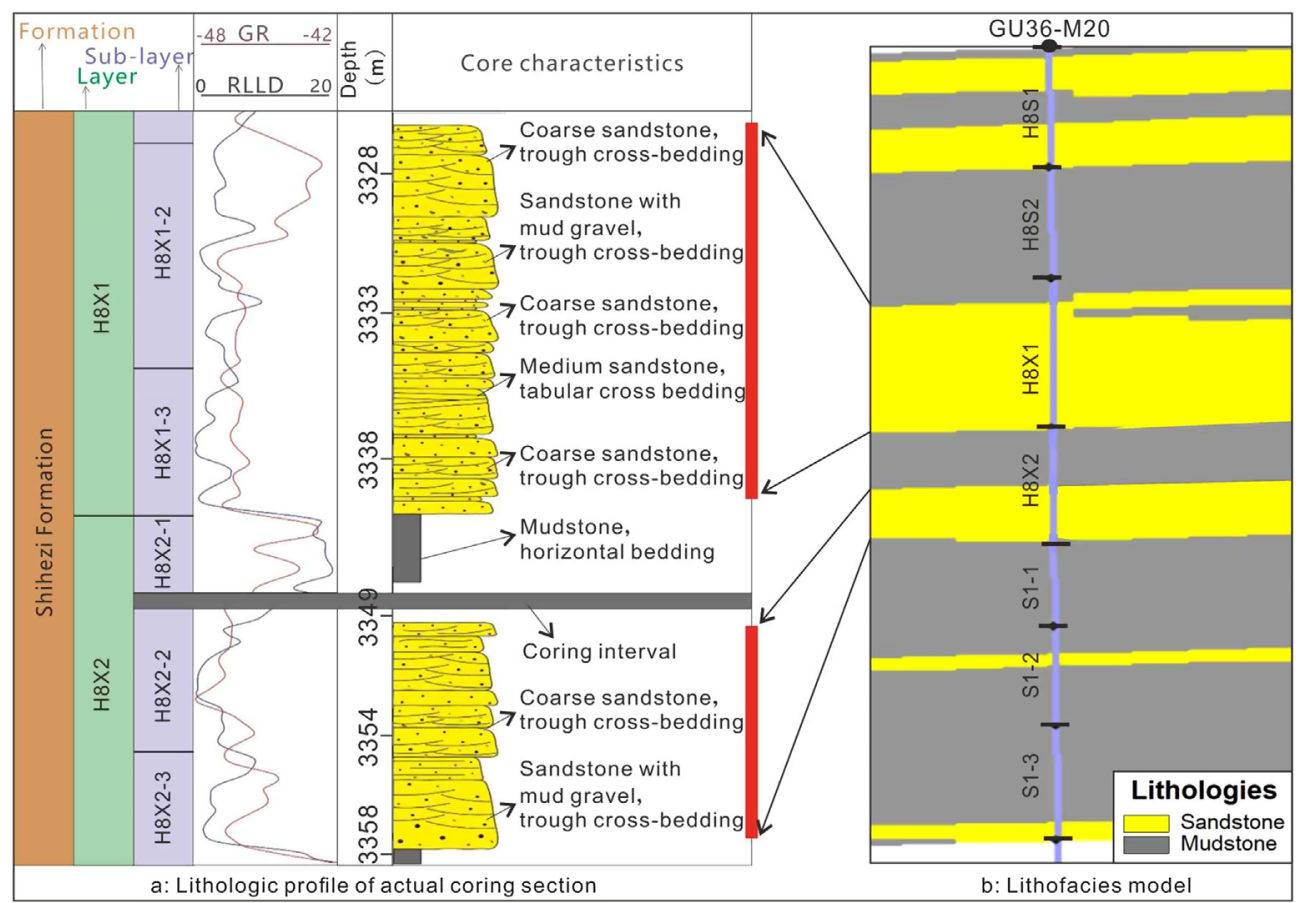

Fig. 16. Test results of single well thinning.

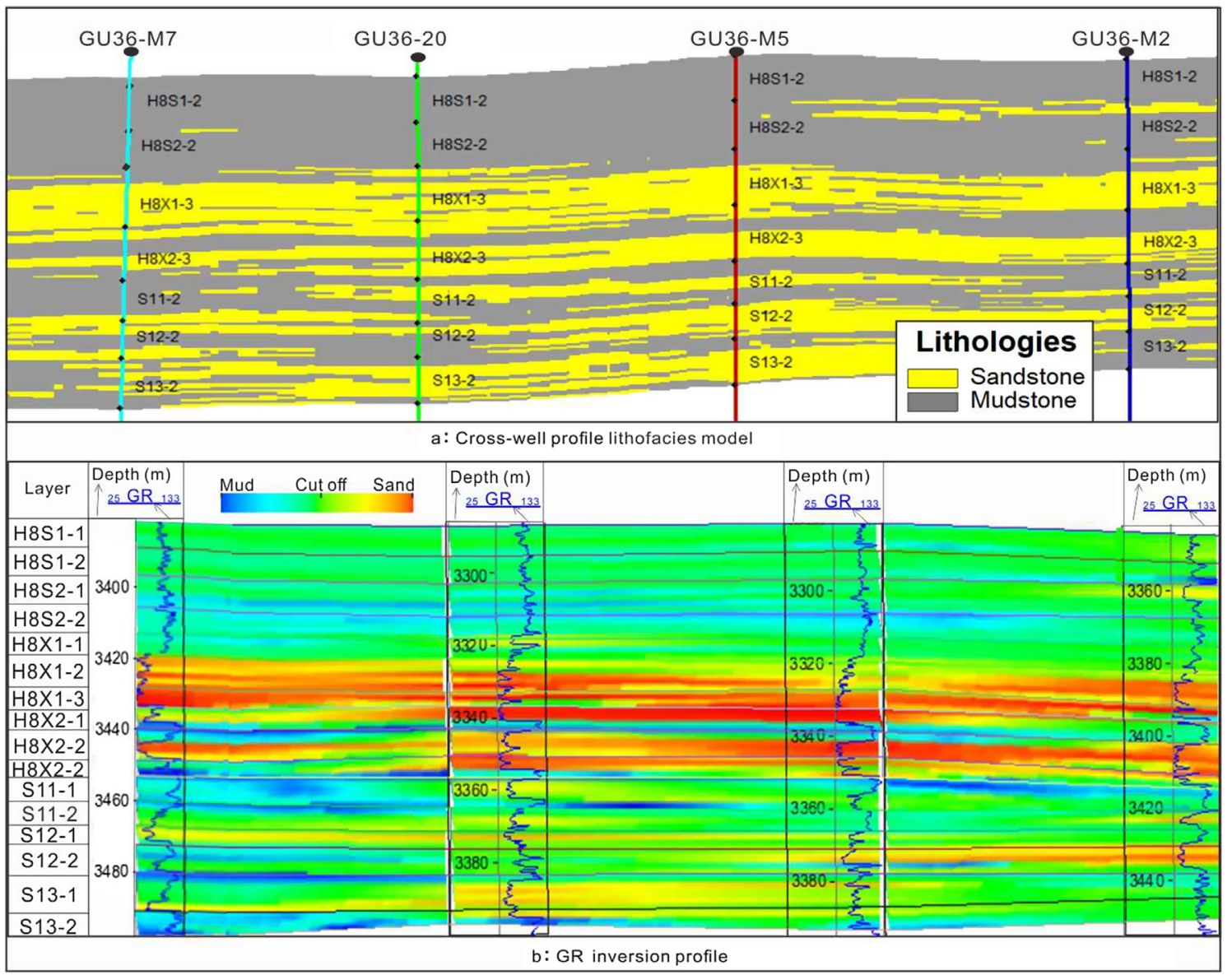

Fig. 17. Test results of multiple well thinning. 


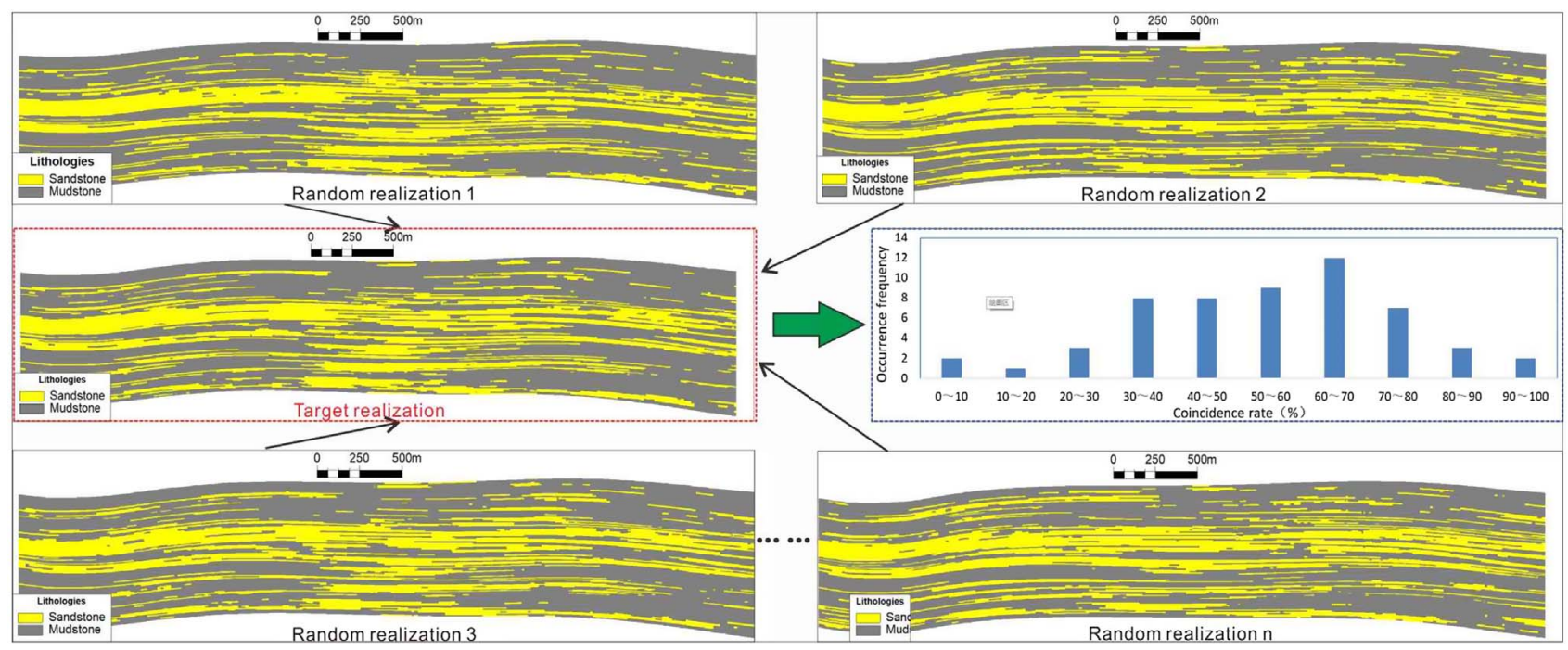

Fig. 18. Results of random seed test.

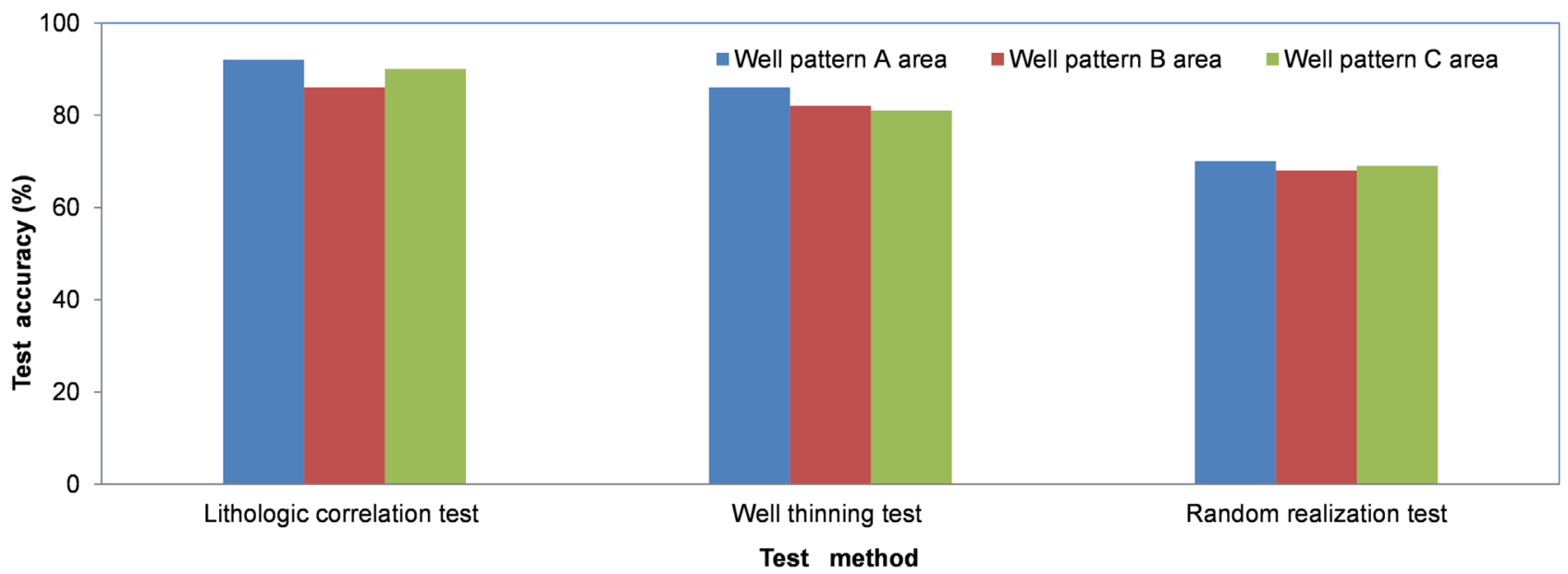

Fig. 19. Test results for the variogram range value of the variogram function of different well patterns.

removed from the model so that it is not included in the interpolation calculation. Then, the lithofacies model generated by the model is compared with the actual well data to verify its compliance. Through comparison and analysis, it can be concluded that the actual single well facies profile (Fig. 16a) is highly consistent with the simulated lithofacies model profile (Fig. 16b), which shows that under the reasonable variation function constraint, the small fluctuations in well space have little influence on the modelling results, and the variation function used and the model established are highly reliable. The vertical size of the lithofacies model grid is $0.5 \mathrm{~m}$, which ignores some fine vertical variation rhythm. The vertical resolution of lithofacies profile is consistent with that of logging curve, which is $0.125 \mathrm{~m}$. So the vertical continuity of lithofacies profile is better than that of lithofacies model.

Figure 16 shows the test results for the multi-well thinning method. In the process of modelling, wells XA30-M7, XA30-M20 and XA30-M5 are removed at the same time, and the remaining well point data are used to build the lithofacies model. Then, we compare the actual lithologic inversion cross-section (Fig. 17a) with the established lithofacies model (Fig. 17b). The comparison results show that they have a high degree of coincidence, which also shows that the model has a certain degree of reliability.

Because the results of stochastic modelling yield a multisolution, there are multiple model realizations available at the same time [40, 41]. The degree of convergence of these realizations determines the reliability of the model and reflects the adaptability of the variation function used. If the convergence degree of the random model is high, it means that the differences among numerous random realizations are small and that the stability of the model is high; otherwise, it means that the stability of the model is low and that the prediction result is not accurate [42-44]. In this paper, a new method is used to test the convergence degree of the stochastic model; that is, some wells are removed during the modelling process, and certain numbers of stochastic models are obtained by setting different random seeds. Then, the degrees of coincidence between the random 
models and the actual data are compared to determine the goal realization. Finally, multiple groups of random realizations are selected for comparison with the target realization, and their similarity is analysed to evaluate the convergence degree of the whole model. Figure 18 shows the comparison results for several random realizations and target realizations. It can be concluded from the analysis that the probability distribution of the model presents a normal distribution as a whole, and the peak value appears in the range of $60-70 \%$. That is, the random realizations have high similarity, and the accuracy of the model is very high.

\section{Discussion}

Using the same method, the variogram databases of areas B and $\mathrm{C}$ are tested, and the results of these methods are shown in Figure 19. It can be concluded from the comparisons of the test results that all of the models established by the variogram database of the three well patterns have good correspondence with the actual geological parameters. The precision of single well and even multi-well thinning is $70 \%$, the realization of random simulation has good convergence, and the coincidence rate with the goal is more than $60 \%$. This comparison shows that the established database has wide applicability and still makes good predictions for irregular well patterns.

However, we also note that there are still some defects in the test results we have obtained; the highest agreement is only $70 \%$, and there is still much room for improvement. Due to the lack of available sample data at present, the quantitative relationship is only analysed tentatively at this stage, and the reliability of the analytical results needs to be improved by subsequent research.

\section{Conclusion}

1. In this paper, a method of partition modelling is proposed and used to build a large-scale reservoir model with multiple well pattern types. This method has high adaptability for geological bodies with large area, great difference of well pattern density and diversity of well pattern types. The model established by this method has a good correspondence with the actual data.

2. The Sulige gas field is divided into three types of areas according to its well pattern. Several model samples are selected from these three areas to make up their respective model sample databases. Their lithofacies models are established, and the variogram range values of each model are obtained. According to the statistical analysis of these variable range values, a database of major and minor range values corresponding to different well patterns is established.

3. In other areas of the Sulige gas field, samples with similar well patterns are selected to test the accuracy of the variable range database. The test results show that the model established by the variogram database for each well pattern is in good accordance with the actual geological conditions, and their random models also have high convergence. These results indicate that the established database has high adaptability and that the prediction model established with this database is reliable.

Acknowledgments. This work was supported by the National Natural Science Foundation of China (grant number 51504143; grant number 51674156). The authors would like to thank the Sinopec Shengli Oilfield workers for supplying research data. The authors would like to thank Fu Yuxiang and Yan Zhaoxun for the great help in the manuscript revision process.

\section{References}

1 Chen G., Zhao F., Wang J., Zheng H., Yan Y., Wang A., Li J., $\mathrm{Hu}$ Y. (2020) Regionalized multiple-point stochastic geological modeling: A case from braided delta sedimentary reservoirs in Qaidam Basin, NW China, Petrol. Explor. Develop. 42, 638-645.

2 Wu S., Zhang Y., Ringas J.E. (2006) Reservoir stochastic modeling constrained by quantitative geological conceptual patterns, Pet. Sci. 3, 28-33.

3 Cai J., Xu K., Zhu Y., Hu F., Li L. (2020) Prediction and analysis of net ecosystem carbon exchange based on gradient boosting regression and random forest, Appl. Energy 262, 114566.

4 Hao M., Wang D., Deng C., He Z., Zhang J., Xue D., Ling X. (2006) 3D geological modeling and visualization of aboveground and under-ground integration-taking the Unicorn Island in Tianfu new area as an example, Earth Sci. Inf. 12, 465-474.

5 Li S., Zhang C. (2010) Ranking realizations of stochastic modeling based on reservoir static geological parameters, Acta Pet. Sin. 31, 445-448.

6 Yang L., Hyde D., Grujic O., Scheidt C., Caers J. (2019) Assessing and visualizing uncertainty of 3D geological surfaces using level sets with stochastic motion, Comput. Geosci. 122, 54-67.

7 Rezapour A., Ortega A., Sahimi M. (2019) Upscaling of geological models of oil reservoirs with unstructured grids using lifting-based graph wavelet transforms, Transp. Porous Media 127, 661-684.

8 Ebong E.D., Akpan A.E., Ekwok S.E. (2020) Stochastic modelling of spatial variability of petrophysical properties in parts of the Niger Delta Basin, southern Nigeria, J. Pet. Explor. Prod. Technol. 10, 569-585.

9 Chang Y., Bouzarkouna Z., Devegowda D. (2015) Multiobjective optimization for rapid and robust optimal oilfield development under geological uncertainty, Comput. Geosci. 19, 933-950.

10 Schiozer D.J., de Souza dos Santos A.A., de Graça Santos S.M., von Hohendorff Filho J.C. (2019) Model-based decision analysis applied to petroleum field development and management, Oil Gas Sci. Technol. - Rev. IFP Energies nouvelles 74, 46.

11 El Azzab D., Ghfir Y., Miftah A. (2019) Geological interpretation of the rifian foreland gravity anomalies and 3D modeling of their Hercynian granites (Northeastern Morocco), J. Afr. Earth Sci. 150, 584-594.

12 Evren P.C., Mark L., Vitaliy O., Jeremie G., Mark J. (2018) Monte Carlo simulation for uncertainty estimation on structural data in implicit 3-D geological modeling, a guide for disturbance distribution selection and parameterization, Solid Earth 9, 385-402. 
13 Wang Y., Li T., Chen Y., Ma G. (2019) Numerical analysis of heat mining and geological carbon sequestration in supercritical $\mathrm{CO}_{2}$ circulating enhanced geothermal systems inlayed with complex discrete fracture networks, Energy 173, 92-108.

14 Cao W., Shi J.Q., Si G., Durucan S., Korre A. (2018) Numerical modelling of microseismicity associated with longwall coal mining, Int. J. Coal Geol. 193, 30-45.

15 Wang H., Wellmann J.F., Li Z., Wang X., Liang R. (2016) A segmentation approach for stochastic geological modeling using hidden Markov random fields, Math. Geosci. 49, 1-33.

16 Cao B., Luo X., Zhang L., Lei Y., Zhou J. (2020) Petrofacies prediction and 3-D geological model in tight gas sandstone reservoirs by integration of well $\operatorname{logs}$ and geostatistical modelling, Mar. Pet. Geol. 114, 104202.

17 Liu K., Yin D., Sun Y. (2020) The mathematical model of stress sensitivities on tight reservoirs of different sedimentary rocks and its application, J. Pet. Sci. Eng. 193, 107372.

18 Lillah M., Boisvert J.B. (2013) Stochastic distance based geological boundary modeling with curvilinear features, Math. Geosci. 45, 651-665.

19 Burki M., Abu-Khadra A. (2019) Sequence stratigraphic approaches for reservoir modeling, Arshad area, Sirt Basin, Libya, J. Afr. Earth Sci. 151, 1-8.

20 Qadri S.M.T., Islam M.A., Shalaby M.R. (2019) Threedimensional petrophysical modelling and volumetric analysis to model the reservoir potential of the Kupe field, Taranaki basin, New Zealand, Nat. Resour. Res. 28, 369-392.

21 Demyanov V., Backhouse L., Christie M. (2015) Geological feature selection in reservoir modelling and history matching with Multiple Kernel Learning, Comput. Geosci. 85, 16-25.

22 Mohaghegh S.D., Gruic O., Zargari S., Dahaghi A., Bromhal G. (2012) Top-down, intelligent reservoir modelling of oil and gas producing shale reservoirs: Case studies, Int. J. Oil Gas Coal Technol. 5, 3-28.

23 Li J., Yan K., Ren H., Sun Z. (2020) Detailed quantitative description of fluvial reservoirs: A case study of L6-3 Layer of Sandgroup 6 in the second member of Shahejie formation, Shengtuo Oilfield China, Adv. Geo-energy Res. 4, 43-53.

24 Bouzarkouna Z., Ding D., Auger A. (2012) Well placement optimization with the covariance matrix adaptation evolution strategy and meta-models, Comput. Geosci. 16, 75-92.

25 Grana D., Paparozzi E., Mancini S., Tarchiani C. (2013) Seismic driven probabilistic classification of reservoir facies for static reservoir modelling: A case history in the Barents Sea, Geophys. Prospect. 61, 613-629.

26 Junling F., Fengde Z., Zhonghua T. (2017) Discrete fracture network modelling in a naturally fractured carbonate reservoir in the Jingbei oilfield, China, Energies 10, 183.

27 Falivene O., Arbués P., Howell J., Munoz J.A., Fernandez O., Maezo M. (2006) Hierarchical geocellular facies modelling of a turbidite reservoir analogue from the Eocene of the Ainsa basin, NE Spain, Mar. Pet. Geol. 23, 679-701.

28 Cabello P., Falivene O., Lopez-Blanco M., Howell-John A., Pau A., Emilio R. (2011) An outcrop-based comparison of facies modelling strategies in fan-delta reservoir analogues from the Eocene Sant Llorenc del Munt fan-delta (NE Spain), Pet. Geosci. 17, 65-90.

29 Wang J., Zhang J., Xie J., Ding F. (2014) Initial gas full component simulation experiment of Ban-876 underground gas storage, J. Nat. Gas Sci. Eng. 18, 131-136.
30 Naji H., Hakimi M., Khalil M., Sharief F. (2010) Stratigraphy, deposition, and structural framework of the cretaceous (review) and 3D geological model of the lower cretaceous reservoirs, Masila oil field, Yemen, Arab. J. Geosci. 3, 221-248.

31 Soleimani M., Shokri B. (2016) Intrinsic geological model generation for chromite pods in the Sabzevar ophiolite complex, NE Iran, Ore Geol. Rev. 78, 138-150.

32 Liu H., Chen S., Hou M., He L. (2020) Improved inverse distance weighting method application considering spatial autocorrelation in 3D geological modeling, Earth Sci. Inf. 13, 619-632.

33 Milicich S.D., Pearson-Grant S.C., Alcaraz S., White P., Tschritter C. (2018) 3D geological modelling of the Taupo Volcanic Zone as a foundation for a geothermal reservoir model, New Zealand, J. Geol. Geophys. 61, 79-95.

34 Jung H., Jo H., Kim S., Lee K., Choe J. (2018) Geological model sampling using PCA-assisted support vector machine for reliable channel reservoir characterization, J. Pet. Sci. Eng. 167, 396-405.

35 Maschio C., Schiozer D.J. (2019) Integration of geostatistical realizations in data assimilation and reduction of uncertainty process using genetic algorithm combined with multi-start simulated annealing, Oil Gas Sci. Technol. - Rev. IFP Energies nouvelles 74, 73.

36 Hazarika P., Yadav A., Roy S. (2017) Influence of permeability in modeling of reservoir triggered seismicity in Koyna region, western India, J. Geol. Soc. India 90, 728-732.

37 Chen L., Yang Z., Liu H. (2017) Sensitivity analysis for the total nitrogen pollution of the Danjiangkou reservoir based on a 3-D water quality model, Front. Earth Sci. 11, 609-619.

38 Wang S., Li Z., Wang S., Han X. (2018) Well pattern optimization based on StoSAG algorithm, Adv. Geo-energy Res. 2, 103-112.

39 Wang X., Wan L., Jiang Z., Liu R., Wang X., Tang W., Gao Y., Liu S., Xu W. (2017) Controlling factors and accumulation model of hydrocarbon reservoirs in the Upper Cretaceous Yogou formation, Koulele area, Termit basin, Niger, $J$. Earth Sci. 28, 1126-1134.

40 Wang J., Zhang J., Xie J. (2018) Determination of the microstructure of a lithologic Interface using the delayed response characteristics of HorizontalWell gamma ray logging curves: A case study of the Daqingzijing oilfield, Songliao basin, northeast China, Arab. J. Sci. Eng. 43, 6653-6664.

41 Yuan B., Zhang Z., Clarkson C. (2019) Improved distance-ofinvestigation model for rate-transient analysis in a heterogeneous unconventional reservoir with nonstatic properties, SPE J. 24, 2362-2377.

42 Wang H., Wellmann J.F., Li Z., Wang X., Liang R. (2017) A segmentation approach for stochastic geological modeling using hidden Markov random fields, Math. Geosci. 49, 145-177.

43 Gengxin C., Fan Z., Jiangong W., Hongjun Z., Yaozu Y., Aiping W., Jiyong L., Yunpeng H. (2015) Regionalized multiple-point stochastic geological modeling: A case from braided delta sedimentary reservoirs in Qaidam basin, NW China, Petrol. Explor. Develop. 42, 697-704.

44 Zhang S., Liu Z., Shi A., Wang X. (2019) Development of accurate well models for numerical reservoir simulation, $A d v$. Geo-Energy Res. 3, 250-257. 